\title{
NUMERICAL RADIUS INEQUALITIES FOR SQUARE-ZERO AND IDEMPOTENT OPERATORS
}

\author{
Hwa-Long Gau, Chin-Ying Huang And Pei Yuan Wu
}

Abstract. We show that if $A$ is a square-zero or an idempotent operator on a Hilbert space and $B$ commutes with $A$, then $w(A B) \leqslant \min \{w(A)\|B\|,\|A\| w(B)\}$ holds, where $w(\cdot)$ and $\|\cdot\|$ denote, respectively, the numerical radius and operator norm of an operator

Mathematics subject classification (2000): 47A12.

Key words and phrases: Numerical range, numerical radius, square-zero operator, idempotent operator.

\section{REFERENCES}

[1] K. Gustafson And D. K. M. RaO, Numerical Range. The Field of Values of Linear Operators and Matrices, Springer, New York, 1997.

[2] P. R. Halmos, A Hilbert Space Problem Book, 2nd ed., Springer, New York, 1981.

[3] J. A. R. HolbROOK, Multiplicative properties of the numerical radius in operator theory, J. Reine Angew. Math., 237 (1969), 166-174.

[4] C.-Y. HuAnG, Numerical Radius Inequalities for Square-zero and Idempotent Matrices, Master thesis, National Chiao Tung Univ., 2005.

[5] V. MüLLER, The numerical radius of a commuting product, Michigan Math. J., 35 (1988), 255-260.

[6] D. K. M. RAO, Rango numerico de operadores commutativos, Rev. Colombiana Mat., 27 (1994), 231-233.

[7] S.-H. Tso AND P. Y. WU, Matricial ranges of quadratic operators, Rocky Mountain J. Math., 29 (1999), $1139-1152$.

[8] P. Y. WU, H.-L. GAU AND M. C. TsaI, Numerical radius inequality for $C_{0}$ contractions, Linear Algebra Appl. (to appear). 